\title{
Non-nosocomial healthcare-associated left-sided Pseudomonas aeruginosa endocarditis: a case report and literature review
}

Hideharu Hagiya ${ }^{1 *}$, Takeshi Tanaka ${ }^{2}$, Kohei Takimoto ${ }^{3}$, Hisao Yoshida ${ }^{1}$, Norihisa Yamamoto ${ }^{1}$, Yukihiro Akeda ${ }^{1}$ and Kazunori Tomono ${ }^{1}$

\begin{abstract}
Background: With the development of invasive medical procedures, an increasing number of healthcare-associated infective endocarditis cases have been reported. In particular, non-nosocomial healthcare-associated infective endocarditis in outpatients with recent medical intervention has been increasingly identified.

Case presentation: A 66-year-old man with diabetes mellitus and a recent history of intermittent urethral self-catheterization was admitted due to a high fever. Repeated blood cultures identified Pseudomonas aeruginosa, and transesophageal echocardiography uncovered a new-onset severe aortic regurgitation along with a vegetative valvular structure. The patient underwent emergency aortic valve replacement surgery and was successfully treated with 6 weeks of high-dose meropenem and tobramycin. Historically, most cases of $P$. aeruginosa endocarditis have occurred in the right side of the heart and in outpatients with a history of intravenous drug abuse. In the case presented, the repeated manipulations of the urethra may have triggered the infection. Our literature review for left-sided $P$. aeruginosa endocarditis showed that non-nosocomial infection accounted for nearly half of the cases and resulted in fatal outcomes as often as nosocomial cases. A combination therapy with anti-pseudomonal beta-lactams or carbapenems and aminoglycosides may be the preferable treatment. Medical treatment alone may be effective, and surgical treatment should be carefully considered.
\end{abstract}

Conclusions: We presented a rare case of native aortic valve endocarditis caused by $P$. aeruginosa. This case illustrates the importance of identifying the causative pathogen(s), especially for outpatients with a recent history of medical procedures.

Keywords: Healthcare-associated infective endocarditis, Patent foramen ovale, Right-to-left shunt, Urethral self-catheterization

\section{Background}

Infective endocarditis (IE) continues to be associated with high morbidity and mortality, even with advancements in medical care. Most cases of IE occur outside of the healthcare setting, but an increasing number of healthcareassociated IE (HCA-IE) are consistently being reported [1]. According to a recent prospective, multicenter, cohort

\footnotetext{
* Correspondence: highgear@hp-infect.med.osaka-u.ac.jp

${ }^{1}$ Division of Infection Control and Prevention, Osaka University Hospital, 2-15 Yamadaoka, Suita, Osaka 565-0871, Japan

Full list of author information is available at the end of the article
}

study, $16 \%$ of IE cases (127/793) were categorized as HCA-IE [2]. Further, a clinically important new type of IE, non-nosocomial healthcare-associated IE (NNHCA-IE), which is defined as IE cases originating from outpatients who underwent medical cares in community settings, has been identified in recent years [2]. These cases of NNHCA-IE account for between 9.3 and $15.7 \%$ of all cases of IE [3-6].

Pseudomonas aeruginosa is typically associated with nosocomial infections. Whereas, the organism is historically known to cause community-acquired IE, which 
develops primarily in the right side of the heart of patients with a history of intravenous drug (IVD) abuse [7, 8]. Due to an increase in invasive medical interventions, cases of $P$. aeruginosa-induced HCA-IE have also recently increased [9]. However, the incidence of $\mathrm{P}$. aeruginosa endocarditis is still significantly low compared to the incidence of endocarditis due to other pathogens [10], and the clinical characteristics of the infection are not well known. Herein, we report a case of left-sided NNHCAIE caused by $P$. aeruginosa, along with a review of the recent literature.

\section{Case presentation}

A 66-year-old man with a history of diabetes mellitus, benign prostatic hypertrophy, and hypertension had recently undergone percutaneous coronary intervention and was transferred to a hospital owing to a high fever and temporary loss of consciousness. The patient had been diagnosed with diabetes mellitus 8 months prior to the hospital admission with markedly elevated blood glucose and hemoglobin $\mathrm{A}_{1} \mathrm{c}$ levels (12.4\%). After the initiation of intensive insulin therapy, the patient's serum glucose level was well controlled. The patient had undergone transurethral resection of the prostate 9 years earlier for treatment of urinary retention secondary to benign prostatic hypertrophy. However, urinary retention persisted, and the patient's symptoms had been managed by an indwelling urinary catheter at home for 6 months. Ten days prior to the onset of fever, he had begun intermittent urethral self-catheterization.

The patient's vital signs on admission were relatively stable. Although focal neurological symptoms were absent, magnetic resonance imaging of the head showed multiple acute emboli in the left parietal and posterior lobes. Blood and urine culture detected antimicrobialsusceptible $P$. aeruginosa, and treatment of ceftazidime (4 g per day) was initiated. Because of his sustained fever, blood cultures were redrawn on day 7 , and they were positive for ceftazidime-resistant $P$. aeruginosa. Antibiotic therapy was changed to levofloxacin (500 mg per day) and continued for 2 weeks. During the hospitalization, transthoracic echocardiography (TTE) was performed twice (on day 1 and day 4), but no remarkable findings were observed. The patient's symptoms resolved with antibiotic treatment, and he was discharged.

Three days after discharge, the high fever remerged, and the patient was readmitted. Physical examination did not show any abnormalities, but laboratory results showed elevated levels of white blood cells $(9300 / \mu \mathrm{L})$ and serum protein $(12.5 \mathrm{mg} / \mathrm{dL})$. Blood culture again detected $P$. aeruginosa, and magnetic resonance imaging of the head showed newly formed, multiple emboli accompanying micro-hemorrhages at the cerebral cortex and cerebellum bilaterally. IE was suspected, but TTE performed on the day of readmission did not reveal any structural abnormalities. Three days later, however, transesophageal echocardiography (TEE) revealed a movable, hypoechoic lesion at the aortic valve, along with new-onset severe aortic regurgitation (Fig. 1a). A patent foramen ovale (PFO) was also discovered (Fig. 1b). The patient was transferred to our hospital for emergency surgical treatment.

On arrival, a pan-diastolic murmur was auscultated, but there was no apparent peripheral embolic finding. Full body computed tomography did not reveal any other infectious foci. $P$. aeruginosa was repeatedly identified in blood cultures, and the antimicrobial susceptibility testing of the pathogen revealed the following minimum inhibitory concentrations: piperacillin, $\geq 128 \mu \mathrm{g} / \mathrm{mL}$; ceftazidime, $\geq 32 \mu \mathrm{g} / \mathrm{mL}$; cefepime, $16 \mu \mathrm{g} / \mathrm{mL}$; aztreonam, $\geq 32 \mu \mathrm{g} / \mathrm{mL}$; imipenem/cilastatin, $1 \mu \mathrm{g} / \mathrm{mL}$; meropenem, $\leq 0.5 \mu \mathrm{g} / \mathrm{mL}$; gentamicin, $4 \mu \mathrm{g} / \mathrm{mL}$; tobramycin, $\leq 1 \mu \mathrm{g} / \mathrm{mL}$; amikacin, $8 \mu \mathrm{g} / \mathrm{mL}$; ciprofloxacin, $\leq 0.25 \mu \mathrm{g} / \mathrm{mL}$; and levofloxacin, $\leq 0.5 \mu \mathrm{g} / \mathrm{mL}$. An emergency operation for aortic valve replacement and PFO closure was performed, and a combination therapy of high-dose meropenem (6 g divided into 3 doses per day) and a single daily dose of tobramycin (300 mg per day, approximately $3.5 \mathrm{mg} / \mathrm{kg} /$ day) was initiated perioperatively. The post-operative clinical course

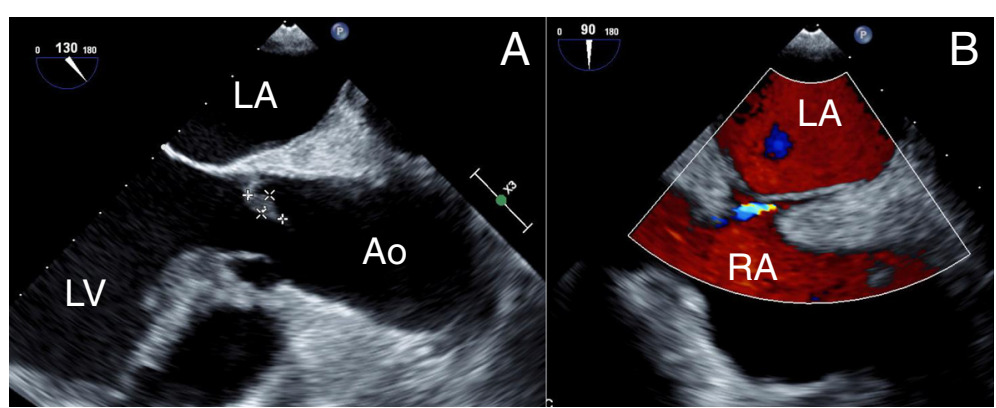

Fig. 1 Transesophageal echocardiography findings. Vegetative lesions are visualized at the right coronary cusp ( $3 \times 12 \mathrm{~mm})$ and the noncoronary cusp $(6 \times 12 \mathrm{~mm})$ of the aortic valve with the presence of newly developed severe aortic regurgitation (a). An interatrial shunt, suggesting the presence of patent foramen ovale, as demonstrated on color Doppler ultrasonography (b). LA left atrium, LV left ventricle, Ao ascending aorta 
was uneventful, and the patient completed a 6-week course of the combination antibiotic therapy. The dose of tobramycin was adjusted to target trough levels of 1 to $2 \mu \mathrm{g} / \mathrm{mL}$, and the patient did not develop renal dysfunction during the treatment. The patient recovered well without recurrence after 1 year.

\section{Discussion}

$P$. aeruginosa endocarditis is a clinically rare condition. In an international study including 61 hospitals in 28 countries, the pathogen accounted for only $0.4 \%(11 / 2761$ cases) of all cases of IE [10]. Compared to right-sided disease, the left-sided $P$. aeruginosa endocarditis progresses rapidly with varied complications and serious outcomes [10]. According to a recent literature review summarizing 40 cases of the left-sided $P$. aeruginosa endocarditis in non-IVD abusers, the overall mortality was about $64 \%$ (23/36 cases) [11]. However, most of the cases were reported more than 10 years previously, and current incidence and clinical features of this rare but fatal infection are uncertain.

For better comprehension of the left-sided $P$. aeruginosa endocarditis, we performed a review of literature published in the last decade (2005 to June 2015) in the MEDLINE database. Due to its low incidence, previous reports referring to HCA-IE did not particularly focus on this pathogen [2-5]. To the best of our knowledge, this is the first attempt to categorize such cases by their clinical backgrounds. A summary of 26 cases identified in the review (15 reports), including the presented case, is shown in Table 1 [11-25].

There were 3 cases of community-acquired IE, 10 cases of NNHCA-IE, and 8 cases of nosocomial healthcareassociated IE (NHCA-IE). Five cases were inconclusive for their onset. Most cases were related to previous history of medical intervention. Involvements of the native valves were common ( $65.4 \%, 17 / 26$ cases), and systemic and cardiac complications occurred in approximately one-third (8/26 cases) and one-fifth (5/25 cases) of the cases, respectively. The mortality rate among patients with NNHCA-IE ( $50 \%, 5 / 10$ cases) was almost as high as that among patients with NHCA-IE (62.5\%, 5/8 cases). For outpatients, we generally do not suspect $P$. aeruginosa as a potential pathogen for IE, and thus, anti-pseudomonal agents are not empirically prescribed. We stress the importance of identifying the causative pathogen(s) in every cases of IE, especially in cases with a recent history of medical intervention.

The primary pathogen entry was undetermined in nearly half of the cases. Our patient repeatedly underwent urinary tract manipulations, and $P$. aeruginosa was noted in his urine sample. In addition, the urinary tract is reported to be a major site of pathogen entry in native valve endocarditis [26]. Moreover, it is known that genitourinary instrumentation accounts for the third most common etiology of HCA-IE, following vascular and digestive origination [2]. Thus, we suspect the damaged urethral mucosa was the pathogen entry site in the presented case. A similar case was also described in a recent NNHCA-IE case [11].

Compared to IVD abusers, who primarily develop right-sided infection, patients without a history of IVD abuse are prone to left-sided infection. A recent report demonstrated that $63 \%$ (17/27 cases) of patients diagnosed with $P$. aeruginosa endocarditis without a history of IVD abuse developed left-sided heart infections [9]. Our review also revealed IVD abuse was less frequently associated with the left-sided $P$. aeruginosa endocarditis (23\%, 6/26 cases). This may be explained by the fact that a high-velocity blood jet stream damages the endocardium, and thus, the left side of the heart is more vulnerable to infection. Although the clinical significance is unknown, the presence of PFO may have been partially responsible for the left-sided involvement in this case.

Optimal treatment for the left-sided $P$. aeruginosa endocarditis has yet to be determined. Effectiveness of combination therapy with carbapenem and aminoglycosides for the infection has been reported [27], and therefore, we treated our patient with meropenem and tobramycin. Of the 26 cases reviewed, combination antibiotic therapy was prescribed in 21 cases $(81 \%)$. Monotherapy with ceftazidime was given in 1 case, but the patient died eventually [16]. Four cases did not mention antibiotic treatment. Among 14 successful cases, 5 patients underwent medical treatment alone, and 4 of them were treated with a combination of anti-pseudomonal beta-lactams and aminoglycosides. Of 9 successful cases with surgical treatment, the similar combined treatment was given in 6 cases. Although the effectiveness of antimicrobial combination therapy remains controversial, it may be preferable when the potential emergence of drug resistant strains during treatment is considered [28], as seen in our case. Thus, we consider that anti-pseudomonal beta-lactams or carbapenems combined with aminoglycosides can be a choice for cases of left-sided $P$. aeruginosa endocarditis.

The need for surgical intervention in the treatment for left-sided $P$. aeruginosa endocarditis should be carefully considered, as recent literature reports that the disease can be successfully treated medically $[25,27]$. However, the results of our review show that the mortality rate in patients receiving medical treatment alone $(62 \%, 8 / 13$ cases) was twice as high as that in patients receiving surgical treatment (31\%, 4/13 cases). The patients were not randomized, and critically ill patients or patients who had severe concomitant diseases tended to be treated by a medical approach alone. Thus, it is actually difficult to compare the survival rates of patients with medical or surgical treatment. However, medical treatment alone 
Table 1 A summary of cases of left-sided infective endocarditis caused by Pseudomonas aeruginosa reported during the last decade (2005-2015)

\begin{tabular}{|c|c|c|c|c|c|c|c|c|c|c|c|}
\hline No. [ref] & Year & Age/Sex & IVD & $\begin{array}{l}\text { Underlying disease or } \\
\text { intervention }\end{array}$ & Suspected source & Infected valves & Size and lesion & Complications & Treatment & Antibiotics & Outcome \\
\hline \multicolumn{12}{|c|}{ Community-acquired IE } \\
\hline $1[12]$ & 2009 & $49 / M$ & Yes & CKD & IVD & Prosthetic mitral/aortic & $10 \mathrm{~mm} / 5 \mathrm{~mm}$ & Unknown & Surgical & $B L+A G$ & Survival \\
\hline $2[13]$ & 2013 & $41 / M$ & No & None & Unknown & Native mitral & $20 \mathrm{~mm}$ & n.d. & Surgical & $B L+A G$ & Survival \\
\hline $3[14]$ & 2013 & $85 / F$ & No & $H T, D M$ & Unknown & Native mitral & $4-8 \mathrm{~mm}$ & $A V B$ & Medical & $B L+A G$ & Death \\
\hline \multicolumn{12}{|c|}{ Non-nosocomial healthcare-associated IE (NNHCA-IE) } \\
\hline $4[15]$ & 2005 & $56 / F$ & No & DM & Unknown & Native mitral & $17 \mathrm{~mm}$ & Meningitis & Medical & $B L+A G$ & Survival \\
\hline $5[16]$ & 2008 & $66 / M$ & No & Cardiac surgery (AVR) & Unknown & Prosthetic mitral & $11 \times 12 \mathrm{~mm}$ & $\begin{array}{l}\text { Sub-endocardial } \\
\text { abscess }\end{array}$ & Surgical & $B L$ & Death \\
\hline $6[11]$ & 2011 & $71 / \mathrm{M}$ & No & $\begin{array}{l}\text { Cardiac surgery (CABG), } \\
C A D \text {, }\end{array}$ & $\begin{array}{l}\text { Urinary tract } \\
\text { (cystoscopy) }\end{array}$ & Native mitral & $6 \times 10 \mathrm{~mm}$ & Cerebral embolism & Surgical & $C P M+F Q$ & Survival \\
\hline $7[11]$ & 2011 & $65 / M$ & No & Cardiac surgery (AD), DM & Infected toe & Prosthetic aortic & n.d. & $\begin{array}{l}\text { Aortic root graft } \\
\text { abscess }\end{array}$ & Surgical & $B L+A G$ & Survival \\
\hline $8[11]$ & 2011 & $45 / M$ & No & $\begin{array}{l}\text { Cardiac surgery (AVR, MVR, } \\
\text { TAP), HD }\end{array}$ & Cardiac surgery & Prosthetic mitral & n.d. & n.d. & Medical & n.d. & Death \\
\hline $9[11]$ & 2011 & $61 / M$ & No & Cardiac surgery (e.g. AVR) & Cardiac surgery & Prosthetic aortic & n.d. & n.d. & Surgical & $B L+A G$ & Death \\
\hline $10[17]$ & 2012 & $63 / M$ & No & $\begin{array}{l}\text { DM, CHF, Implanted } \\
\text { pacemaker, CKD }\end{array}$ & Unknown & Native mitral & $5 \mathrm{~mm}$ & Aortic root abscess & Surgical & $B L+A G$ & Death \\
\hline $11[18]$ & 2012 & $73 / \mathrm{M}$ & No & $\begin{array}{l}\text { MM, HT, DM, Af, } \\
\text { chemotherapy }\end{array}$ & $\begin{array}{l}\text { Infection of the } \\
\text { lower limb }\end{array}$ & Native mitral & $10 \mathrm{~mm}$ & n.d. & Medical & $B L+F Q$ & Death \\
\hline $12[19]$ & 2012 & $49 / F$ & No & $\mathrm{DM}, \mathrm{CAD}, \mathrm{CKD}(\mathrm{HD}), \mathrm{HT}$ & Dialysis catheter & Native aortic & $20 \mathrm{~mm}$ & n.d. & Medical & $B L+A G$ & Survival \\
\hline $13^{\mathrm{a}}$ & 2015 & $66 / M$ & No & $\mathrm{DM}, \mathrm{BPH}, \mathrm{HT}, \mathrm{CAD}$ & Urinary tract & Native aortic & $6 \times 12 \mathrm{~mm}$ & Cerebral infarction & Surgical & $C P M+A G$ & Survival \\
\hline \multicolumn{12}{|c|}{ Nosocomial healthcare-associated IE (NHCA-IE) } \\
\hline $14[20]$ & 2008 & $45 / F$ & No & Severe burn & Burn injury & Native aortic & n.d. & None & Medical & n.d. & Death \\
\hline $15[20]$ & 2008 & $47 / F$ & No & Severe burn & Burn injury & Native mitral & $3 \times 10 \mathrm{~mm}$ & $\begin{array}{l}\text { Cerebral and renal } \\
\text { embolism }\end{array}$ & Medical & n.d. & Death \\
\hline $16[20]$ & 2008 & $31 / M$ & No & Severe burn & Burn injury & Native mitral & $3 \times 5 \mathrm{~mm}$ & Cerebral embolism & Medical & n.d. & Death \\
\hline $17[21]$ & 2009 & $69 / M$ & No & Cardiac surgery (AVR) & Unknown & Prosthetic aortic & n.d. & Unknown & Surgical & $\mathrm{FQ}+\mathrm{AG}$ & Survival \\
\hline 18 [22] & 2012 & $35 / M$ & No & Renal transplantation & Surgery & Native aortic & $6 \times 13 \mathrm{~mm}$ & Splenic infarction & Medical & $\mathrm{CPM}+\mathrm{FQ}$ & Survival \\
\hline $19[23]$ & 2014 & $83 / \mathrm{M}$ & No & HD, CHF, Malignancy & Unknown & Prosthetic aortic & $8 \mathrm{~mm}$ & Heart failure & Medical & $\mathrm{CPM}+\mathrm{COL}$ & Death \\
\hline 20 [23] & 2014 & $55 / M$ & No & Immunosuppressive therapy & Unknown & Native aortic & $14 \mathrm{~mm}$ & Splenic infarction & Surgical & $\mathrm{CPM}+\mathrm{COL}$ & Death \\
\hline $21[24]$ & 2014 & $60 / M$ & No & Myocardial infarction & Unknown & Native mitral & n.d. & Splenomegaly & Surgical & $\mathrm{BL}+\mathrm{AG}$ & Survival \\
\hline
\end{tabular}


Table 1 A summary of cases of left-sided infective endocarditis caused by Pseudomonas aeruginosa reported during the last decade (2005-2015) (Continued)

\begin{tabular}{|c|c|c|c|c|c|c|c|c|c|c|c|}
\hline \multicolumn{12}{|c|}{ Uncertain cases } \\
\hline $22[25]$ & 2009 & Unknown & Yes & Unknown & IVD & Prosthetic aortic & $3 \mathrm{~mm}$ & Yes & Medical & $\mathrm{BL}+\mathrm{AG}$ & Survival \\
\hline $23[25]$ & 2009 & Unknown & Yes & Unknown & IVD & Native mitral & $4 \mathrm{~mm}$ & Yes & Medical & $\mathrm{BL}+\mathrm{AG}$ & Survival \\
\hline $24[25]$ & 2009 & Unknown & Yes & Unknown & IVD & Native aortic & $6 \mathrm{~mm}$ & Yes & Surgical & $B L+A G$ & Survival \\
\hline 25 [25] & 2009 & Unknown & Yes & Unknown & IVD & Prosthetic mitral & $10 \mathrm{~mm}$ & Yes & Surgical & $\mathrm{BL}+\mathrm{AG}$ & Survival \\
\hline 26 [25] & 2009 & Unknown & Yes & Unknown & IVD & Native aortic & $15 \mathrm{~mm}$ & Yes & Medical & $\mathrm{BL}+\mathrm{FQ}$ & Death \\
\hline
\end{tabular}

$A D$ aortic dissection, $A F$ atrial fibrillation, $A G$ aminoglycoside, $A V B$ atrioventricular block, $A V R$ aortic valve replacement, $B L$ anti-pseudomonal beta-lactam, $B P H$ benign prostatic hypertrophy, $C A B G$ coronary artery bypass grafting, CAD coronary artery disease, CHF chronic heart failure, CKD chronic kidney disease, COL colistin, CPM carbapenem, DM diabetes mellitus, FQ fluoroquinolone, HT hypertension, IE infective endocarditis, IVD intravenous drug use, MM multiple myeloma, MVR mitral valve replacement, SSS sick sinus syndrome, TAP tricuspid annuloplasty, n.d. not described

Non-nosocomial healthcare-associated cases are those that occurred in outpatients who had received medical care prior to the onset of infection

${ }^{a}$ Case No. 13 is the present case 
may be insufficient for left-sided $P$. aeruginosa endocarditis in some cases. A prospective, randomized study is warranted to elucidate the appropriate treatment strategy for this type of infection.

\section{Conclusions}

In conclusion, we described a rare case of left-sided NNHCA-IE caused by $P$. aeruginosa. The repeated manipulation of the urethra by intermittent selfcatheterization was suspected as the cause of the infection. A literature review of cases of left-sided $P$. aeruginosa endocarditis revealed that non-nosocomial cases accounted for nearly half of the cases, and resulted in fatal outcomes as often as that noted in nosocomial cases. Optimal treatment is undetermined, but combination therapy with anti-pseudomonal betalactams or carbapenems and aminoglycosides would be preferable, according to the results of our review. Surgical indication for the disease should be carefully determined in every case.

\section{Abbreviations}

CA-IE, community-acquired IE; HCA-IE, healthcare-associated IE; IE, infective endocarditis; IVD, intravenous drug; NHCA-IE, nosocomial healthcare-associated IE; NNHCA-IE, non-nosocomial healthcare-associated IE; PFO, patent foramen ovale; TEE, transesophageal echocardiography; TTE, transthoracic echocardiography.

\section{Acknowledgements}

We would like to thank all medical staff who cared for the patient.

\section{Funding}

None to report.

\section{Availability of data and materials}

None to describe.

\section{Authors' contributions}

$\mathrm{HH}$ mainly collected data and drafted the manuscript. $\Pi$ and $\mathrm{KT}$ managed the patient at the clinical site and gave advice in drafting. HY, NY, YA, and KT participated in interpretation and discussion. KT finally approved the article. All authors read and approved the final manuscript.

\section{Competing interests}

The authors declare that they have no competing interests.

\section{Consent for publication}

Written informed consent was obtained from the patient for publication of this case report and any accompanying images. A copy of the written consent is available for review by the Editor of this journal.

\section{Ethics approval and consent to participate}

Involvement of the ethical committee was not considered necessary, since this case report was not classified as a research study.

\section{Author details}

${ }^{1}$ Division of Infection Control and Prevention, Osaka University Hospital, 2-15 Yamadaoka, Suita, Osaka 565-0871, Japan. '2Department of Cardiovascular Surgery, Osaka University Hospital, Osaka, Japan. ${ }^{3}$ Department of Anesthesiology and Intensive Care Medicine, Osaka University Hospital, Osaka, Japan.

Received: 20 October 2015 Accepted: 4 August 2016 Published online: 20 August 2016

\section{References}

1. Fernandez-Hidalgo N, Almirante B, Tornos P, Pigrau C, Sambola A, Igual A et al. Contemporary epidemiology and prognosis of health care-associated infective endocarditis. Clin Infect Dis. 2008:47:1287-97.

2. Lomas JM, Martinez-Marcos FJ, Plata A, Ivanova R, Galvez J, Ruiz J, et al. Healthcare-associated infective endocarditis: an undesirable effect of healthcare universalization. Clin Microbiol Infect. 2010;16:1683-90.

3. Benito N, Miro JM, de Lazzari E, Cabell CH, del Rio A, Altclas J, et al. Health care-associated native valve endocarditis: importance of non-nosocomial acquisition. Ann Intern Med. 2009;150:586-94.

4. Wu KS, Lee SS, Tsai HC, Wann SR, Chen JK, Sy CL, et al. Non-nosocomial healthcare-associated infective endocarditis in Taiwan: an underrecognized disease with poor outcome. BMC Infect Dis. 2011;11:221.

5. Yang F, Zhang B, Yu J, Shao L, Zhou P, Zhu L, et al. Epidemiology and the prognosis of healthcare-associated infective endocarditis in China: the significance of non-nosocomial acquisition. Emerg Microbes Infect. 2015;4, e38.

6. Murdoch DR, Corey GR, Hoen B, Miro JM, Fowler Jr VG, Bayer AS, et al. Clinical presentation, etiology, and outcome of infective endocarditis in the 21st century: the International Collaboration on Endocarditis-Prospective Cohort Study. Arch Intern Med. 2009;169:463-73.

7. Reyes MP, Palutke WA, Wylin RF. Pseudomonas endocarditis in the Detroit Medical Center. 1969-1972. Medicine (Baltimore). 1973;52:173-94.

8. Cohen PS, Maguire JH, Weinstein L. Infective endocarditis caused by gramnegative bacteria: a review of the literature, 1945-1977. Prog Cardiovasc Dis. 1980;22:205-42

9. Lin Tl, Huang YF, Liu PY, Chou CA, Chen YS, Chen YY, et al. Pseudomonas aeruginosa infective endocarditis in patients who do not use intravenous drugs: analysis of risk factors and treatment outcomes. J Microbiol Immunol Infect. 2014

10. Morpeth S, Murdoch D, Cabell CH, Karchmer AW, Pappas P, Levine D, et al. Non-HACEK gram-negative bacillus endocarditis. Ann Intern Med. 2007;147: 829-35.

11. Dawson NL, Brumble LM, Pritt BS, Yao JD, Echols JD, Alvarez S. Left-sided Pseudomonas aeruginosa endocarditis in patients without injection drug use. Medicine (Baltimore). 2011;90:250-5.

12. Daas H, Abuhmaid F, Zervos M. Successful treatment of Candida parapsilosis and Pseudomonas aeruginosa infection using medical and surgical management in an injecting drug user with mitral and aortic valve endocarditis: a case report. J Med Case Rep. 2009;3:6598.

13. Yilmaz M, Sunar H, Mert A. Community-acquired left-sided Pseudomonas aeruginosa endocarditis in a patient without intravenous drug use. Infection. 2013:41:243-5.

14. Setoguchi M, Iwasawa E, Hashimoto $Y$, Isobe M. A patient with infective endocarditis caused by community-acquired Pseudomonas aeruginosa infection. Intern Med. 2013;52:1259-62.

15. Venkatesan A, Spalding C, Speedie A, Sinha G, Rumbaugh JA. Pseudomonas aeruginosa infective endocarditis presenting as bacterial meningitis. J Infect. 2005;51:e199-202.

16. Reinsch N, Plicht B, Lind A, Janosi RA, Buck T, Kamler M, et al. Recurrent infective endocarditis with uncommon Gram-negative Pasteurella multocida and Pseudomonas aeruginosa: a case report. J Heart Valve Dis. 2008;17:710-3.

17. Aggarwal A, Ritter N, Reddy L, Lingutla D, Nasar F, El-Daher N, et al. Recurrent Pseudomonas aortic root abscess complicating mitral valve endocarditis. Heart Lung. 2012;41:181-3.

18. Todaro J, Bollmann PW, Nussbacher A, Camargo LF, Santos BF, Alvarenga D, et al. Multiple myeloma complicated with pseudomonas endocarditis. Einstein (Sao Paulo). 2012:10:498-501.

19. Hassan KS, Al-Riyami D. Infective endocarditis of the aortic valve caused by Pseudomonas aeruginosa and treated medically in a patient on haemodialysis. Sultan Qaboos Univ Med J. 2012;12:120-3.

20. Regules JA, Glasser JS, Wolf SE, Hospenthal DR, Murray CK. Endocarditis in burn patients: clinical and diagnostic considerations. Burns. 2008;34: 610-6.

21. Kato $Y$, Ohashi $H$, Tsutsumi $Y$, Murakami T, Takahashi Y. Prosthetic valve endocarditis caused by metallo-beta-lactamase-producing Pseudomonas aeruginosa. J Card Surg. 2009;24:347-9.

22. Nasim A, Baqi S, Akhtar SF. Pseudomonas aeruginosa endocarditis in renal transplant recipients. Transpl Infect Dis. 2012;14:180-3.

23. Durante-Mangoni E, Andini R, Agrusta F, lossa D, Mattucci I, Bernardo M, et al. Infective endocarditis due to multidrug resistant gram-negative bacilli: single centre experience over 5 years. Eur J Intern Med. 2014;25:657-61. 
24. Polovina M, Potpara T, Milosevic I, Stepanovic J, Jovanovic M, Pavlovic M. Mitral valve endocarditis caused by Pseudomonas aeruginosa: a case report. J Infect Dev Ctries. 2014;8:676-9.

25. Reyes MP, Ali A, Mendes RE, Biedenbach DJ. Resurgence of Pseudomonas endocarditis in Detroit, 2006-2008. Medicine (Baltimore). 2009;88:294-301.

26. Meyers BR, Sherman E, Mendelson MH, Velasquez G, Srulevitch-Chin E, Hubbard M, et al. Bloodstream infections in the elderly. Am J Med. 1989;86: 379-84.

27. Gavin PJ, Suseno MT, Cook FV, Peterson LR, Thomson Jr RB. Left-sided endocarditis caused by Pseudomonas aeruginosa: successful treatment with meropenem and tobramycin. Diagn Microbiol Infect Dis. 2003;47:427-30.

28. Fichtenbaum CJ, Smith MJ. Treatment of endocarditis due to Pseudomonas aeruginosa with imipenem. Clin Infect Dis. 1992;14:353-4.

Submit your next manuscript to BioMed Central and we will help you at every step:

- We accept pre-submission inquiries

- Our selector tool helps you to find the most relevant journal

- We provide round the clock customer support

- Convenient online submission

- Thorough peer review

- Inclusion in PubMed and all major indexing services

- Maximum visibility for your research

Submit your manuscript at www.biomedcentral.com/submit
Biomed Central 